\title{
How the diurnal hours affects maintenance behavior in Japanese quail concerning rearing modification systems
}

\author{
Shereen EL-Sayed Abdel-Hamid D. Azhar Fakhry Abdel Fattah iD
}

\section{SE Abdel-Hamid - AF Abdel Fattah (Corresponding} author)

Department of Veterinary Public Health, Faculty of veterinary medicine, Zagazig University, Zagazig, Ash Sharqia Governorate 44519, Egypt.

\author{
email: azharfakhry478@gmail.com
}

Received: June 14, 2020 • Accepted: July 15, 2020 • Published Online: July 26, 2020

\begin{abstract}
This study was carried out to investigate the impact of times of day on the behavior of Japanese quail concerning managerial modifications systems. A total of 120 one-day-old quail chicks were used in this study. 60 chicks were housed in cage systems; distributed into 3 subgroups (20 birds on each), a normal cage group, a cage with cover as wire floor with plastic cover from the top and third cage group "Edinburg modification cage", as a normal cage except that the front portion has dust bather filled with washed builder sand or fine sawdust. The other floor managerial modifications included 60 birds distributed into three subgroups. The first-floor group was considered "normal", as 20 birds were housed using an $80 \times 50$ floor system with $5 \mathrm{~cm}$ or $10 \mathrm{~cm}$ dry, clean soft sawdust sprinkling with slaked lime, the second-floor group was named "A grill group". The feed was offered to the quail in a plastic feeder covered with the grill to reduce feed wastage and the third-floor group offered feed to the quail in a longitudinal constructed feeder with six holes separated by wire. Data were analyzed using two-way ANOVA, where two factors affect the behavior of quails and from our study, we suggested that there were non-significant differences in the ingestive behavior of quail regarding the daylight effect. Most standing frequencies were conducted midday at most managerial modifications. Crouching time also increased in the early morning with the normal floor group and constructed feeder. We conclude that various times of the day and managerial modifications greatly alter maintenance behavior in most quail chicks. Abnormal behavior was comparatively higher in the morning.
\end{abstract}

Keywords: Coturnix japonica, diurnal times, maintenance behavior, managerial modification, managerial system

\section{Introduction}

Japanese quail production has been increased among the poultry industry since its start as a commercial poultry activity. Quail has excellent meat quality, high nutritional value, and pleasant flavor of its eggs, which has resulted in wide consumer acceptance. However, its production faces some challenges. The spotlight mounted directly to the net minimizes netter illumination by positioning the light source away from the netter's body (Martins 2002). Circadian rhythms are the most critical factor that affects their behavior. (Troy et al 2012). The eye activity rhythm of Japanese quail controls circadian behavior, which directly affects rhythmicity. The light has an important impact on poultry behavior and physiology (Taniguchi et al 1993). Day length has a clear impact on patterns of behavioral expression in broiler chickens during the photo phase (Lewis and Morris 1998).

The Edinburgh modified cage of quail rearing is normal cage deck but at the front portion of the cage, there was a nest box as dust bather filled with fine wood shaving. In the free access version, birds had a free opportunity to the nest box and dust bath at all times (Appleby and Hughes 1995). The ingestive behavior was improved with floor managed quail in the early morning while quail reared at cages showed the highest level of feeding in the late afternoon. The crouching time was increased with mid-day at caged reared quail (AbdelHamid et al 2019).

Thus, our study was conducted to record the effects of different times of day in the broilers' behaviors (Mohammed et al 2017, Bookers et al 2004) the behavior can aid in the interpretation of an animal's feelings, both positive (such as playful, relaxed, and exploratory behaviors) and negative (including frustration, fear, or pain). This study was carried out in Japanese quail to investigate how the time of day influences quail behavior regarding rearing modification systems.

\section{Materials and Methods}


This study was conducted with Japanese quail (Coturnix coturnix japonica) to investigate the impact of diurnal periods on the behavior of quail related to managerial modifications systems. The study was carried out at two housing systems at the experimental building belonging to the Faculty of Veterinary Medicine at Zagazig University in Egypt. The research protocol was approved by the Institutional Animal Care And Use Committee and Zagazig University (Approval No. ZU-IACUC/2/F/2/2019).

\section{Birds and housing condition}

Two housing systems housed 120 one-day-old quail chicks. Half of the chicks were housed in cage systems; the other half was housed using a deep-litter floor. Cage systems were divided into three groups, each including 20 birds that were distributed into two laying cages. The measures of each cage were $60 \times 50 \times 25 \mathrm{~cm}$ and noted as the normal cage group, named "cage with cover", consisted of a wire floor replaced with fine sawdust and topped with a plastic cover to avoid head injuries. The third cage group was named the "Edinburg

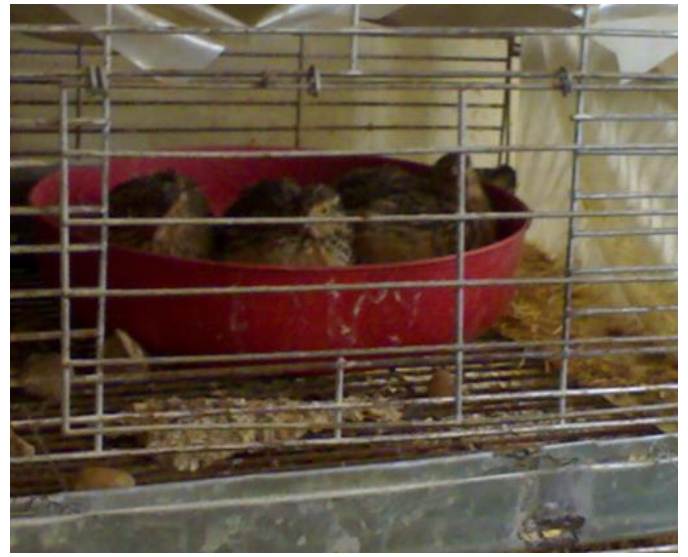

A

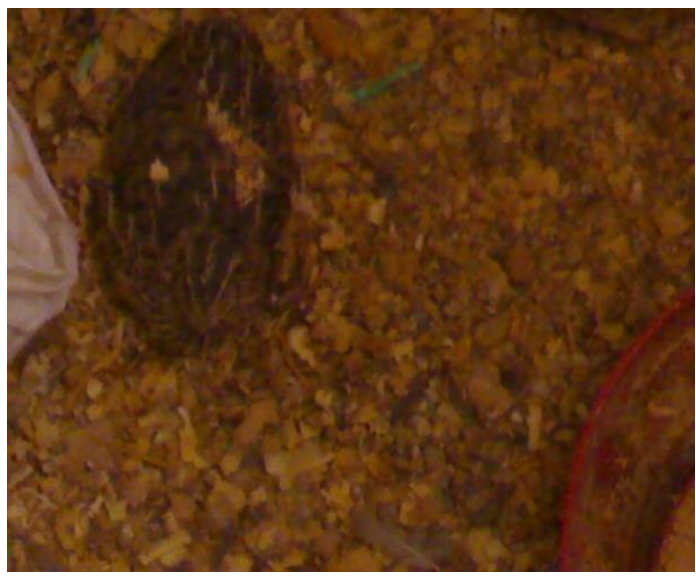

C modification cage", which comprised a normal cage except that the front portion was included with dust bather filled with washed builder sand or fine sawdust to offer chicks the opportunity for dust bathing. The multi-decked cage group, the battery consists of 5 tires vertically cages as each tire was contained two laying cage with dimension $(60 \times 50 \times 25 \times 20 \mathrm{am})$ was given a wire mesh floor to prevent quail dropping accumulation.

According to Abdel-Hamid (2009), the other floor managerial modifications included 60 birds distributed into three groups. The first-floor group was considered "normal", as 20 birds were housed using an $80 \times 50$ floor system with $5 \mathrm{~cm}$ or $10 \mathrm{~cm}$ dry, clean soft sawdust sprinkling with slaked lime. The second-floor group was named "A grill group". Throughout the study, the feed was offered to the quail in a plastic feeder covered with the grill to reduce feed wastage. The third-floor group offered feed to the quail in a longitudinal constructed feeder with six holes separated by wire partitions. Figure 1 illustrates the shape of modified managerial systems and bird sitting behavior on it.

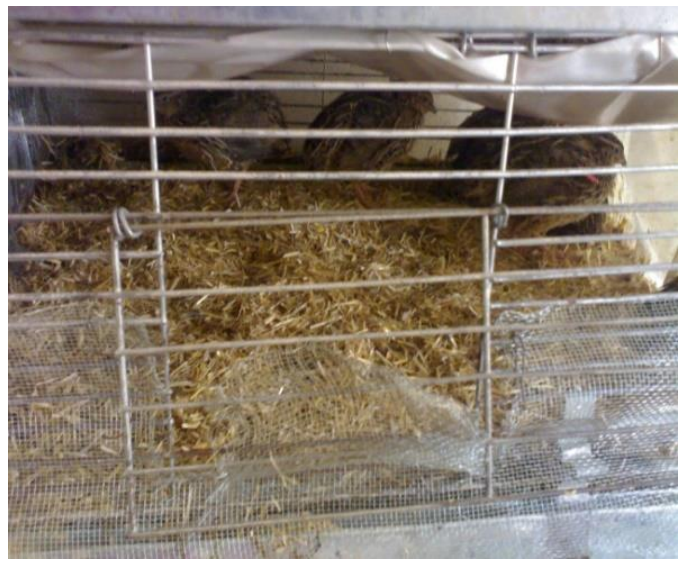

B

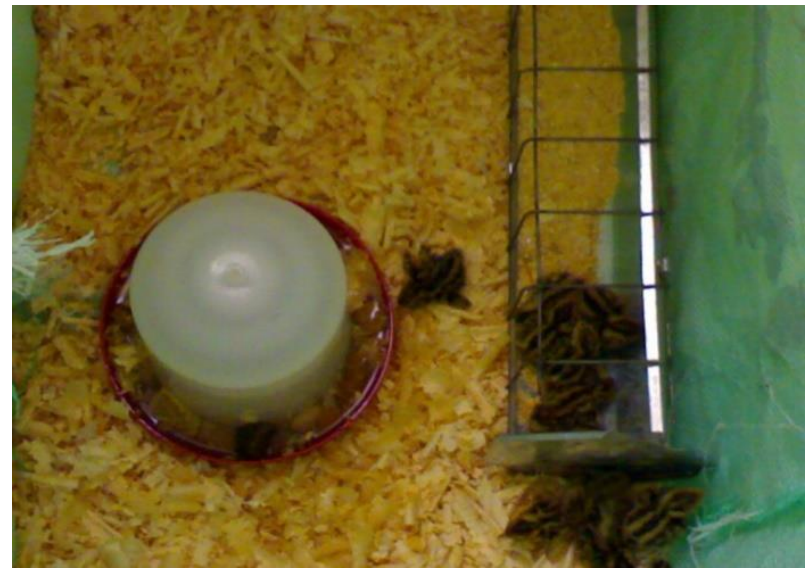

$\mathrm{D}$

Figure 1 Modified managerial systems and bird sitting behavior on it. A) Modified quail cage with a dust bath as normal cage deck but at the front part of the cage, there was a nest box that was designed as dust bather filled with sand or fine sawdust. B) Modified quail cage with cover cage decks was covered with white plastic table cloth at the top of the cage to avoid head injuries and mortality. C) Crouching behavior: Laying or sitting breast on the floor, locking about or with closed eyes. D) Constructed feeder at floor management which was divided into 6 longitudinal holes separated by wire partition each hole sufficient for one bird. 
Food and water were available ad-libitum, with feed consisting of as yellow corn $(56.10 \%)$, crude protein $(24.9 \%)$, soybean meal (32.73\%), crude fiber (3.45\%), fishmeal (5.50\%), metabolized energy (3909 MJ/kg), calcium \& phosphorus $(1.23 \%)$, and other feed additives $(1.9 \%)$. The temperature was maintained at about $35^{\circ} \mathrm{C}$ during the first week of brooding and was then decreased by about $3-5^{\circ} \mathrm{C}$ weekly until the birds were full-feathered (3 to 4 weeks). Each bird was identified by the group using colored wing bands to differ between groups (Abdel-Hamid 2019). Natural light was offered during daytime hours, and continuous light was programmed with using a 200 -watt lamp nightly. The birds were administered two intervals of vitamins $A, D_{3}, E$, and supplemented with $\mathrm{Ca}$, ph. Anti-coccidian drugs were also administered.
Behavioral observation was conducted using and recording a focal sample technique. The behavioral observation in both systems, floor, and cage, were recorded at 6-minute intervals during 12-hour observation periods per week to represent different times of day: (P1) Early morning: 7-11 hours period; (P2) Midday: 11-15 hours; and (P3) Late afternoon: 15-19 hours. The observed behavioral patterns were recorded as shown in Table 1.

\section{Statistical analysis}

All statistical analyses were performed using SPSS software, V.16 (SPSS Inc., Chicago, IL, USA). Data were analyzed using two-way ANOVA, where two factors affect the behavior of quails: first-factor is the modification system in quail rearing and second-factor are various day times, according to Duncan (1955).

\section{Observation technique}

Table 1 Behavioral patterns (Dawkins 2004).

\begin{tabular}{|c|c|}
\hline Behavior & Definition \\
\hline \multicolumn{2}{|l|}{ 1- Ingestive: } \\
\hline a-Feeding & Head extended towards available feed resources while beak in or above the drinker \\
\hline \multirow[t]{3}{*}{ b-Drinking } & appears \\
\hline & to be manipulating or ingesting feed \\
\hline & quails obtained water from drinking resource \\
\hline 2- Standing behavior & Quails were standing idle and not engaged in any activity. \\
\hline 3- Walking & Moves forward taking one or more steps. \\
\hline 4- Running & Moving rapidly not walking. \\
\hline 5-Crouching & Quails lying on the ground. \\
\hline \multicolumn{2}{|l|}{ 6-Comfort behavior: } \\
\hline a-Feather preening & Birds clean and care about their plumage with their beak using short and repeated action \\
\hline b-Other comfort behavior: & while standing or sitting. \\
\hline Wing flapping & in which the bird stretches its full height and flaps its wings repeatedly. \\
\hline Body shaking & in which the bird shakes its body vigorously \\
\hline \multicolumn{2}{|c|}{ 7-Abnormal behavior (Abdel-Hamid 2009): } \\
\hline a-Wall pecking & $\begin{array}{l}\text { The ambivalent behavior (characterized by an aggressive action followed immediately by } \\
\text { submissive posture) during feeding competition was observed in both the unstable and } \\
\text { stable grouping of caged quail }\end{array}$ \\
\hline b- Food wastage & $\begin{array}{l}\text { Quails waste the feed by scratching at the feeder with its legs by jumping in or out the } \\
\text { feeder }\end{array}$ \\
\hline c-Aggressive pecking & $\begin{array}{l}\text { The ambivalent behavior (characterized by an aggressive action followed immediately by } \\
\text { submissive posture) }\end{array}$ \\
\hline
\end{tabular}

\section{Results}

All cage rearing system modifications showed no significant differences in feeding times between different times of day, although most managerial modifications increased in the afternoon (Table 2). There were significant differences in walking activity, with increases in the late afternoon during dust bathing and in the early morning with the cage cover. Time of day affected ingestive and kinetic behavior of quail in all cage types.

The preening and other comfort behavior significantly increased in the early morning in both the normal cage and covered cage; these behaviors increased in the late afternoon in the cage with dust bathing (Table 3). Each group presented a significant effect regarding comfort and behavioral disorders based on time of day.

Means of the ingestive and kinetic behavior of quail reared under different floor modifications to different times of day are shown in Table 4. It clearly shows there was no significant effect on feeding, drinking, or walking and running behavior. However, each group's ingestive and kinetic behavior was significantly affected by the time of day.

The impact time of day had on comfort and behavioral disorders of quail reared under different floor modifications to different day times are presented in Table. 5. It shows that had no significant effect on comfort and behavioral disorder. Each group was significantly affected by the time of day regarding the birds' comfort and behavioral disorders. 
Table 2 Ingestive and kinetic behavior of quail reared under different cage modifications at different daytimes periods.

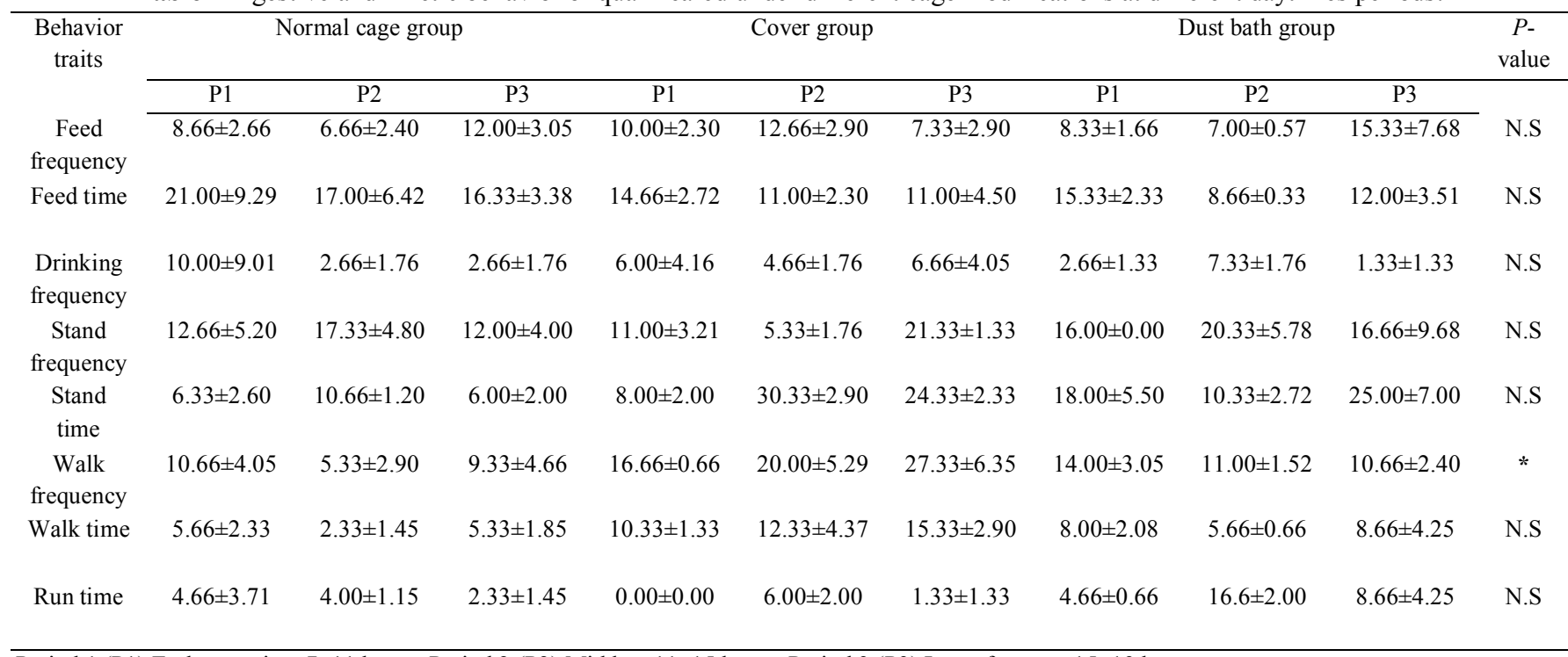

Period 1 (P1) Early morning: 7-11 hours; Period 2 (P2) Midday: 11-15 hours; Period 3 (P3) Late afternoon 15-19 hours

NS: Non-significant changes; *Significant at 0.05 probability; ** Highly significant at 0.01 probability

Table 3 Comfort and behavioral disorders of quail reared under different cage modifications at different times of the day.

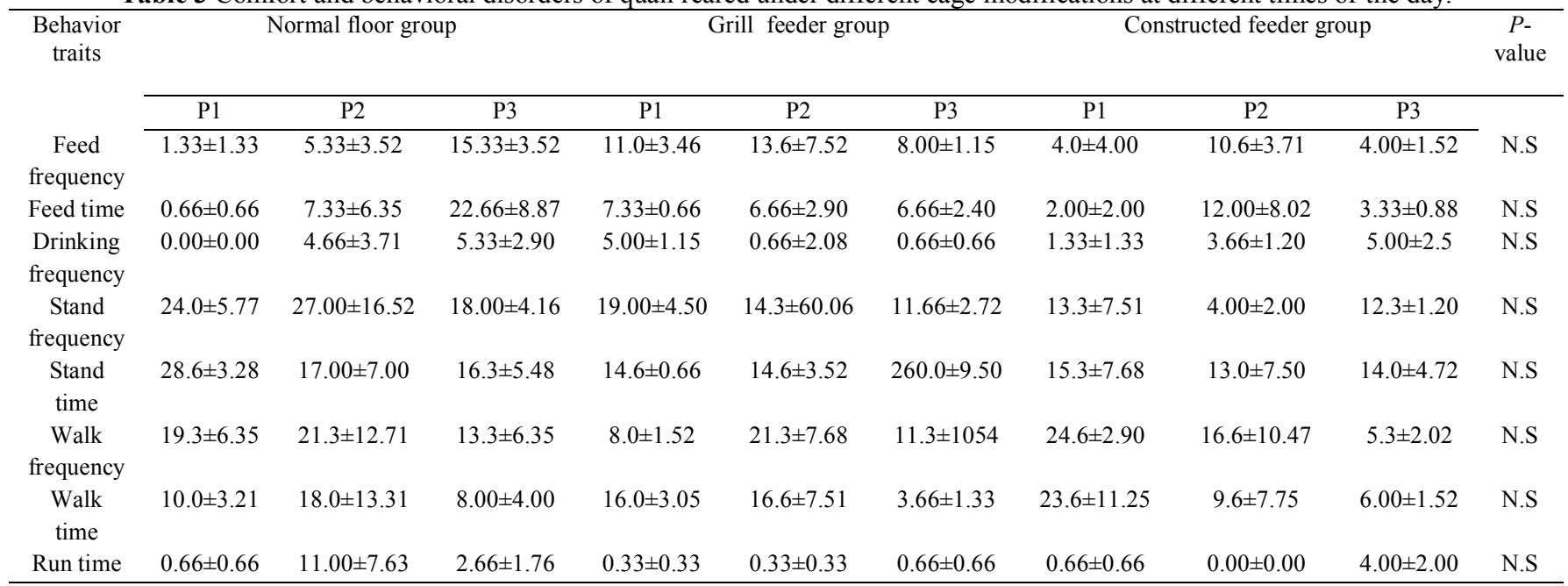

Period 1 (P1) Early morning: 7-11 hours; Period 2 (P2) Midday: 11-15 hours; Period 3 (P3) Late afternoon 15-19 hours

NS: Non-significant changes; *Significant at 0.05 probability; ** Highly significant at 0.01 probability

Table 4 Ingestive and kinetic behavior of quail reared under different floor modifications at different times of the day.

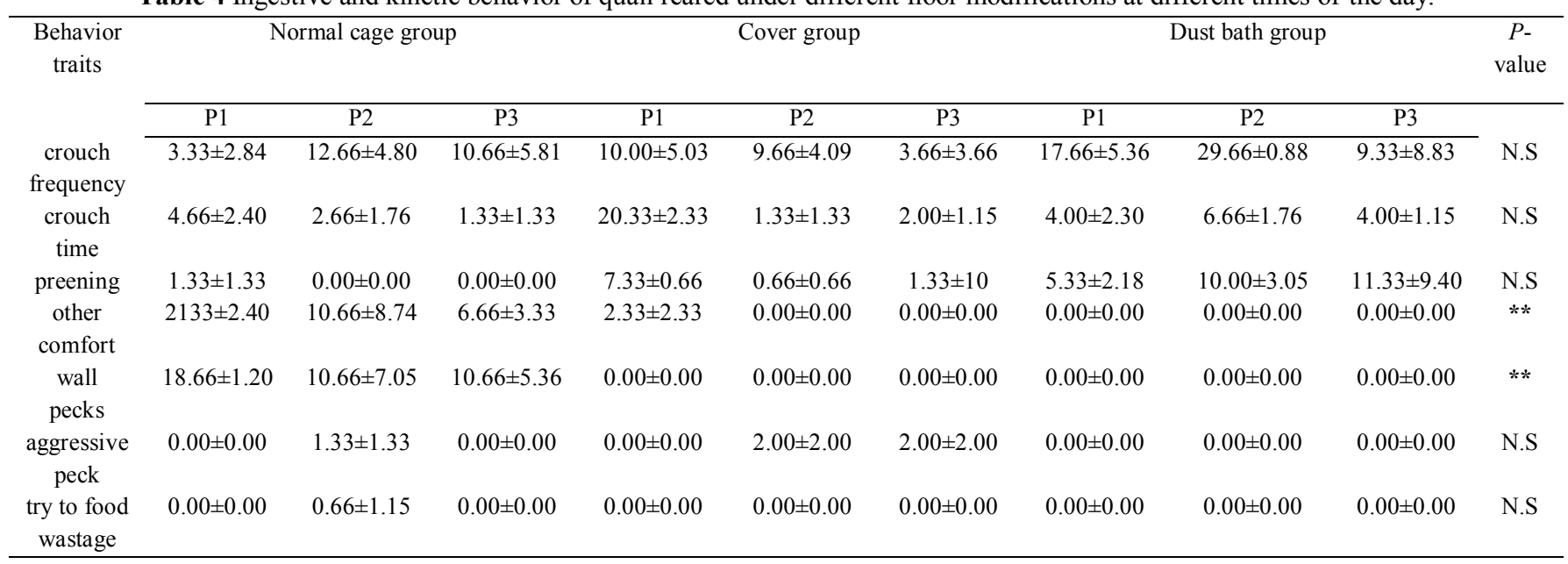


Table 5 Comfort and behavioral disorders of quail reared under different floor modifications at different times of the day.

\begin{tabular}{|c|c|c|c|c|c|c|c|c|c|c|}
\hline \multirow[t]{2}{*}{ Behavior traits } & \multicolumn{3}{|c|}{ Normal floor group } & \multicolumn{3}{|c|}{ Grill group } & \multicolumn{3}{|c|}{ Constructed feeder group } & \multirow{2}{*}{$\begin{array}{c}P- \\
\text { value }\end{array}$} \\
\hline & P1 & $\mathrm{P} 2$ & P3 & $\mathrm{P} 1$ & $\mathrm{P} 2$ & P3 & P1 & $\mathrm{P} 2$ & P3 & \\
\hline $\begin{array}{l}\text { crouch } \\
\text { frequency }\end{array}$ & $8.00 \pm 2.00$ & $15.00 \pm 6.42$ & $9.00 \pm 7.54$ & $15.3 \pm 7.68$ & $19.66 \pm 9.17$ & $4.00 \pm 1.15$ & $6.00 \pm 0.00$ & $2.66 \pm 1.76$ & $17.33 \pm 8.74$ & N.S \\
\hline crouch time & $12.6 \pm 4.861$ & $1.66 \pm 1.76$ & $8.00 \pm 4.61$ & $3.33 \pm 1.76$ & $4.33 \pm 1.85$ & $35.6 \pm 4.25$ & $16.33 \pm 7.16$ & $16.66 \pm 13.17$ & $1.33 \pm 1.33$ & * \\
\hline preening & $3.33 \pm 2.40$ & $1.33 \pm 1.33$ & $0.00 \pm 0.00$ & $1.33 \pm 1.33$ & $2.33 \pm 1.85$ & $0.00 \pm 0.00$ & $8.00 \pm 4.60$ & $3.66 \pm 3.17$ & $10.6 \pm 5.60$ & N.S \\
\hline other comfort & $4.00 \pm 2.30$ & $4.00 \pm 2.00$ & $0.00 \pm 2.00$ & $5.33 \pm 4.37$ & $1.66 \pm 0.88$ & $0.00 \pm 0.00$ & $0.60 \pm 0.66$ & $2.00 \pm 2.00$ & $0.33 \pm 0.33$ & N.S \\
\hline wall pecks & $2.33 \pm 1.45$ & $2.00 \pm 1.00$ & $1.33 \pm 1.33$ & $0.00 \pm 0.00$ & $0.00 \pm 0.00$ & $0.00 \pm 0.00$ & $0.00 \pm 0.00$ & $0.33 \pm 0.33$ & $0.33 \pm 0.33$ & N.S \\
\hline $\begin{array}{c}\text { aggressive } \\
\text { peck }\end{array}$ & $2.00 \pm 2.00$ & $0.00 \pm 0.00$ & $0.00 \pm 0.00$ & $0.00 \pm 0.00$ & $0.00 \pm 0.00$ & $0.00 \pm 0.00$ & $0.00 \pm 0.00$ & $0.00 \pm 0.00$ & $0.00 \pm 0.00$ & N.S \\
\hline $\begin{array}{l}\text { try to food } \\
\text { wastage }\end{array}$ & $0.00 \pm 0.00$ & $3.00 \pm 3.00$ & $1.33 \pm 1.33$ & $4.66 \pm 2.40$ & $3.33 \pm 1.76$ & $0.00 \pm 0.00$ & $0.00 \pm 0.00$ & $0.00 \pm 0.00$ & $0.00 \pm 0.00$ & N.S \\
\hline
\end{tabular}

\section{Discussion}

Lighting is an important external factor in the behavioral patterns of birds, as the photoperiod greatly influences their actions. Furthermore, observing behavior aids in evaluating a bird's welfare. The results shown in Table 2 referred that there were non-significant differences in birds' ingestive behavior relating to daylight effects, with most standing frequencies carried out midday for most managerial modifications. (Vestergaard et al 1990, Lindberg and Nicol 1997) as they studied that dust baths make the attractiveness to feed in the feeder. Because poultry typically does not feed at night, the morning feeding peak allows them to refill their food storage organ (the crop), which becomes depleted overnight. Most standing frequency and crouching behavior occurred midday with most cage modifications and showed significant differences (Martins 2002 and Amado et al.2011) stated that the behavioral pattern of poultry was highest in the early morning and late afternoon. More ever,(Nelson et al.2002 and Newton2007) cited that the circadian hour greatly affected the birds' behavior globally. Dust bathing in poultry is a highly motivated behavior that will occur even in the absence of stimuli as "Sham" or "Vacuum" dust bathing. Some designs of modified cages for laying hens contain dust baths (Abdel-Hamid 2009). These results, shown in Table 3, reference a close relationship with dust bathing frequencies and dusk. According to Abdel-Hamid (2017) mentioned that the preening and feather-shaking frequencies were not affected by diurnal factors,

It was concluded that changes time of day and the lighting duration of quails was significantly correlated to various normal bird behaviors. Abnormal behavior was higher in the morning. Diurnal hours have a weak impact on the birds' behavior as quail reared at a battery system showed the highest level of ingestive behavior in the late afternoon 16 (Lincoln et al 2016). Although, Abdel-Hamid et al (2019) showed that there were non-significant differences in standing time between different times of day in both housing systems. The results are shown in Table 4 indicate that the highest feeding frequency and time occurred midday at most floor modification systems. Additionally, increases were evident in the late afternoon for floor rearing without any modifications. The most standing time was increased with grill rearing quail in the late afternoon, Activity movement increased with midday for most floor rearing. Crouching time (Table 5) was increased in the early morning at the normal floor and constructed feeder cages. There were insignificant differences in preening and other comfort behavior at most times of the day and floor managerial modifications.

The ingestive behavior was higher in the morning than other photoperiods; this may be due to decreased heat stress. Most behavioral patterns of birds were greatly affected by circadian rhythms (Mohammed 2017; Amado et al 2011; Wirminghus et al 2001; Kondo et al 2006). Diurnal hours had no significant effect on wall pecking behavior. These results are supported by the research of (Kundu et al 2003; Khurshid et al 2004). Feed wasting was increased during morning hours, possibly because of increased activity in birds at this time of day. The preening was not affected by different times of day at either housing system (Lincoln et al 2006). The crouching time increased at midday for battery-managed quail compared with floor-reared ones. As, well as (Abdel-Hamid et al 2019) stated that diurnal hours had a significant effect on quail behavior, welfare, and egg-laying rate, all of which are instrumental in daily egg production. We suggest future research should investigate the effects of light duration on sexual behavior, as well as egg quality.

\section{Conclusions}

We concluded that the ingestive behavior increased in cage-managed quail in the afternoon, while floor-reared quail showed the highest level of ingestive behavior at midday. The standing time increased midday with battery-managed quail. 
Aggressive pecking and food wastage rose in the morning, possibly owing to increased activity in the birds at this time of day. Each group was significantly affected by the time of day concerning maintenance and behavioral disorders. Circadian factors affected bird behavior, while light had a significant effect on the birds' behavior, welfare, and egg-laying rate, which contribute to daily egg production. Therefore, the economical effect of photoperiods on quail exists.

We suggest supplying quail with artificial light and increasing exposure hours to increase laying rates, amplify reproductive performance, and improve welfare.

\section{Acknowledgments}

We thank the staff at the Department of Veterinary Public Health, Faculty of Veterinary Medicine, Zagazig University, Egypt for providing materials used in this study. We would also like to thank the anonymous referees for their helpful comments on the manuscript.

\section{Conflict of Interest}

The authors declare no conflict of interest.

\section{References}

Abdel-Hamid SE (2009) Effect of managerial systems on behaviour and performance of quail. Master thesis. Faculty of veterinary Medicine, Zagazig University, Egypt.

Abdel-Hamid SE (2017) Behaviour and management guide of some ornamental birds in relation to diurnal hours. International Journal of Advanced Research, 5:2084-2090.

Abdel-Hamid SE, Gharib SH, Youssef MI, Saleemm AK, Said NE (2019) The influence of photoperiods on behaviour of quail under different housing systems. International Journal of Veterinary Sciences and Animal Husbandry 4:35-39.

Amado M, Diego B, Vanner B, Carla T, Concepta M, Francisco E (2011) Behaviour of captive Ostrich chicks from 10 days to 5 months of age. Revista Brasileira de Zootecnia 40:1613-1618.

AOAC (2002) Official methods of analysis. Association official analytical chemists, Gaithersburg, USA.

Appleby MC, Hughes BO (1995) The Edinburgh modified cage for laying hens. British Poultry Science 36:707-718.

Bokkers EA, Koene MP, Rodenburg TB, Zimmerman PH, Spruijt BM (2004) Working for food under conditions of varying motivation in broilers. Animal Behaviour 68:105-113.

Dawkins M (2004) Using behaviour to assess animal welfare. Animal welfare potters bar then wheath ampstead 13:S3-S8.

Mohammed HH, Said NE, Abdel-Hamid SEL, Nawar AK, Mohamed YI, Al Sadik KY (2017) The effects of the different day times in the changes of behaviour in broilers. $4^{\text {th }}$ International Food Safety Conference, University of Sadat City.

Jensen P (2009) The ethology of domestic animals. 2nd edition, 9:121.
Khurshid A, Farooq M, Durrani FR, Sarbiland K, Manzoor A (2004) Hatching performance of Japanese quais. Livestock Research for Rural Development 16:1-5.

Koenig S (1999) The reproductive biology of Jamaica's black - billed parrot (Amazona agilis) and conservation implications. $\mathrm{PhD}$, Yale University, New Heaven.

Kondo N, Sekijima KT, Takamatsu J, Ohtsu T (2006) Circannual control of hibernation by HP complex in the brain. Cell 125:161-172.

Kundu A, Senani S, Ahlawat SpS, Rai RB, Yadav SP, Chalterjee, RN, Saha SJ, Kumar SJ, Jai S (2003) Japanese quail under cage and deep-litter system of rearing in Andman and Nicobar Island. Journal of Poultry Science 38:63-66.

Lewis PD, Morris TR (1998) Responses of domestic poultry to various light sources. World's Poultry Science Journal 54:72-75.

Lindberg AC, Nicol CJ (1997) Dust bathing on modified battery cages: Is sham dust bathing an adequate substitute: Applied Animal Behaviour Science 55:113-128.

Lincolin G, Clarke I, Hut R, Hazlerigg D (2006) Characterizing a mammalian circannual pace marker. Science 314:1941-1944.

Gebhardt-Henrich SG, Steiger A (2006) Effect of aviary and box sizes on body mass and behaviour of domesticated budgerigars. Animal Welfare 15:353-358.

Martins EN (2002) Perspectivas do melhoramento genético de codornas no Brasil. Proc Simp Int Cot 1:204-208.

Mohammed H H (2017) The Potential Effect of Circadian Rhythms and Lighting Duration on Behaviour and Growth Performance of Quails under Egyptian Condition. Zagazig Veterinary Journal 45:3136.

Nelson R, Demoas G, Klein S, Kriegsfeld L (2002) Seasonal Patterns of Stress, Immune Function, and Disease. Cambridge University Press, New York.

Newton I (2007) The ecology of bird migration London, UK. Academic Press.

Troy RG, Peter S, Coates J, Connelly W, Pocatello 1 (2012) A Modified Night-Netting Technique for Recapturing Quail. Wildlife Society Bulletin 36:578-581.

Chabot CC, Menaker M (1993) Effects of physiological cycles of infused birds, Brain Research 620:297-300.

Vestergaard K, Hogan JA, Kruijt ZP (1990) The development of a behavriour systems: dust bathing in the burmes fed jungle fowl. The influence of the rearing environment on the organization of dust bathing. Behaviour 112:99-116.

Wirminghus J, Downs C, Perrin M, Symes C (2001) Abundance and activity patterns of the cape parrot in two a fromon-tane forests in south Africa. African Zoology 36:71-77. 